\title{
The unspoken reminisces of a medical intern
}

\section{Sabbir ASM}

\section{One side of the coin}

It was around midnight when the hospital premises were invaded by a raucous crowd of thuggish strangers, claiming to be the henchmen of some influential entity. They barged in to the emergency unit and commanded with unwarranted authority'

'Are you the doctor?', he inquired in a colloquial dialect

'Yes, please?'

One of our men has been stabbed, come quickly'.

I hurriedly rushed to the emergency unit, to discover a patient with a grievous stab wound around the spinal cord. A faltering pulse rate of 120 , abnormal blood pressure count of $80 / 40$ and the fatal depth of the wound was more than enough to assess the enormity of the patient's condition.

After consulting a senior colleague, he was injected with emergency medication and saline before he was immediately transferred to the operation theatre. After an absolutely nerve-wracking, gruelling three hour surgery we were finally able to stall the bleeding with three blood bags, but at the inevitable cost of one of his kidneys and a portion of the food pipe. But it was just the beginning of another long, arduous battle as we struggled to save him from a life-threatening trachea inflammation. The several sleepless nights spent by his anxious wife did not go in vain however, as by the grace of almighty and the tireless efforts of the assigned doctor the man was salvaged from the clutches of death for a miraculous second time. After nine days of remission, the man was released from the hospital to avoid any recurring infections.

The incident occurred right after the man was sent back home. The same rouges who had brought the man to the hospital (note that they were not seen anywhere near the patient during the past nine days) reappeared one fine morning and launched a verbal tirade.

'How dare you release our patient on such a short notice', he accused furiously

'This is a hospital so please lower your voice', was my instant retort

'Why should I speak softly', the man continued with his rampage, 'Do you know who I am?'
'Your patient has fully recovered, and that was why we sent him home,' was my cool and curt reply.

'Don't you dare use that tone with me! We decide whether our patient has recovered or not so if you know what's good for you, you better readmit him'.

I realized any kind of rationale was incapable of countering this obdurate man's irascibility, so as helpless as I was; I was compelled to rescind his release papers and start processing the readmission procedure from the day after.

Next morning while rewriting his name on the patient's list I ruminated over yesterday's events and confessed to my patient, with much regret nevertheless '

'The day you were admitted to this hospital in a critically injured state, I was the one who arranged for emergency remedies and I have been the one tending to your wound for the past nine days, and alas this is how you repay me. '

My patient's nonchalant attitude and utter lack of response rendered nothing but a feeling of helplessness and despondency from inside me. Sighing heavily, I the unimportant entity departed with a heavy heart.

\section{The other side of the coin}

A former patient at the hospital suffering from colon cancer, Mr. Hafez was admitted for post-surgery chemotherapy. The persistent man could not be dissuaded from giving me a tip, and despite my repeated assurances that I was a salaried intern and it was my duty to ensure that he received all the necessary treatment every recuperating cancer patient was entitled to, he refused to listen. A police official once came to my room for passport verification and after knowing I was a doctor, instead of demanding some kind of payment, treated me to tea and snacks.

I never have to book my train tickets in advance; rather just one phone call is enough to get me home-bound. I never had to pay extra money ( read bribes) to receive my driving license on time. The reason?

The goodwill of my noble profession.

\section{Epilogue}

An ancient Greek mythological adage goes as such 'If you want a moment of well-being then sleep, if you want a day 
of peace then travel, if you want a month of tranquility then marry, if you want a year of comfort then inherit wealth but if you want a lifetime of happiness, then love your work'

My ephemeral internship experience was a great teacher; it taught me how to love my profession wholeheartedly. At the end of the day it's not just about every healed smile, but also about the countless instances of heartfelt love and compassion that we doctors receive in our lifespan. And we all we need is 1 . Sound knowledge 2. Sound skill 3. Empathy
Then what about criticisms and judgments of your work? Remember, criticisms never encompass the ordinary, but the extraordinary. Legends like Aristotle, Theofrostus, Harvey and Ibne Sina were all subjected to criticisms.

But at the end it is the philosophy of these immortals that lives on while critiques have been drowned by the tides of time...

Dr A S M Sabbir Email: asm.sabbir@gmail.com

\section{Medical Joke}

\section{Smart Doctor}

A Doctor opened a clinic \& wrote outside the clinic: Any treatment will cost Tk.1000 and if we can't treat, we will pay you back Tk. 5000 .

A CLEVER Man comes to do fraud \& thinking to get Tk.5000. He says to the Doctor: I can't feel any taste on my tongue...

Doctor asks the Nurse to put few drops of medicine from box no 22. After that the MAN shouts: "What did you put on my tongue........its URINE!! The doctor says congratulations! Your sense of taste is back now.
The MAN was angry as he lost Tk. 1000. After 2 weeks The MAN comes back again \& this time he thinks to get back his previous Tk. 1000 too.

MAN: Doc! I've lost my memory. Doctor: Nurse! Please put some drops of medicine from Box no. 22 on his tongue.

MAN: Wait doctor but that medicine is for sense of taste. Doctor: Congratulations! Your memory is back now.

Dr S K Murad Medical Officer, Orthopaedic Surgery BSMMU, Dhaka 